\title{
The Possible Serum Complex-Biomarkers for the Early Diagnosis of Diastolic Dysfunction with Preserved Systolic Function
}

\begin{abstract}
BOGDAN IOAN COCULESCU ${ }^{1}$, GHEORGHE MANOLE', ALEXANDRA-LIGIA DINCA², TUDOR HARSOVESCU ${ }^{1}$, IOAN SORIN TUDORACHE ${ }^{1}$

'Titu Maiorescu University Bucharest, Faculty of Medicine, 22 Dambovnicului, 040441, Bucharest, Romania

${ }^{2}$ Specialist doctor, Medicover Hospital Bucharest, 24 Preciziei, 062204, Bucharest, Romania

he present study looks at serum concentration levels of myeloperoxidase (MPO) and high-sensibility $C$ Reactive Protein (hs-PCR) concentrations in 91 patients who presented thoracic pain localised on the subclavicular left side, which bothered them several times a day, where an episode lasted up to 30 minutes. Additional preclinical investigations revealed normal resting state/effort electrocardiograms, and the cardiac ultrasound revealed a diastolic cardiac dysfunction with a conserved ejection fraction. The conclusion of our study is that undertaking the exploratory tetrad (electrocardiogram, echocardiogram, serum dosage of MPO and hs-PCR) in patients who present anterior left pain, regardless of the degree of intensity, allows stratifying risks, at least through early detection of an existent diastolic cardiac dysfunction with conserved ejection fraction, which recommends changes in diet and lifestyle along with therapy.
\end{abstract}

Keywords: reactive oxygen species (ROS), reactive nitrogen species (RNS), myeloperoxidase (MPO), highsensibility C Reactive Protein (hs-CRP)

Cellular oxidative stress is defined as the biological state characterised by an excess concentration of oxidative agents (reactive oxygen species, ROS or reactive nitrogen species, RNS). This arises as a consequence of an intensified synthesis, or a reduction of the antioxidant systems [1,2].

As for all the other organs, oxidative stress as a pathogeny of the heart muscle must be approached as a double action: local production of oxidative agents through the involvement of the muscle's structural cells, migrant cells and infiltrated cells, and through systemic production [3]. In the first category of local cellular sources of oxidative agents are the cardiac muscle fibres, myocytes and vascular endothelial cells, and in the category of migrant elements involved in inflammation are the neutrophils, and especially monocytes which become macrophages [47].

Coronary arteriosclerosis, which is aetiologically responsible for the chronic myocardial malfunction, induces the excessive production of ROS/RNS, thus developing a first stage chronic diastolic dysfunction [8,9].

As part of the evolutionary dynamic of myocardial oxidative stress, the inflammation develops successively and leads to the production of chemoattractant factors which are responsible for the monocyte activation. The control over macrophages activation during inflammation is done by at least 24 factors, importantly: tumour necrosis factor (TNF), interleukin-1 (IL-1) and stimulating factors granulocytes colonies stimulating factor (G-CSF), monocyte colonies stimulating factor (M-CSF). The monocyte activation has three steps: resident/responsive monocytes, partially activated/initiated monocytes and activated monocytes.

Miyloperoxidase is a lysosomal monocyte-macrophage enzyme which catalyses the reaction between oxygenated water and chloride, thus generating hypochlorite and hypochloric acid respectively, which acquired lytic cellular action.
The literature referring to cardiovascular pathology places myeloperoxidases together with matrix metalloproteinases (MPM) and with the CD40 soluble ligand (SCD40L) in the category of biomarkers who indicate an instability and a rupture of the aterom plaque [6]. We also mention that until present, according to our documentation, the role of MPO has notbeen investigated in the myocardial remodelling processes induced through oxidative stress, hence our reasons for the current study.

\section{Experimental part}

Material and method

We aim to look at the increases in serum levels of MPO, which is a marker of myocardial remodelling of the post infarct ventricle and as an indicator of cardiac insufficiency progression, in the context of diastolic dysfunction with conserved ejection fraction in order to see whether there are any similarities. This is because raising serum concentration of this enzyme highlights the presence of an inflammatory process which develops even in hypoxic conditions. Pathogenically, the diastolic cardiac dysfunction evolves on an ischemic cardiopathy background which is characterised by a coronary debit which is unable to provide optimal irrigation required for myocardial activity.

The study sample consisted of patients who presented themselves for a consultation and had symptoms of localised pain in the superior half of the left hemithoracic region, sub-clavicular. The motivation of the study and the choosing of the patient sample are to highlight whether this atypical pain could be a pectoral angina or whether it is a manifestation of an ischaemic painful cardiopathy.

To identify whether myocardial hypoxia was present we undertook resting state and effort (for those who did not show difficulties during resting state tests) electrocardiogram tests for all patients. We did not include the patients who although presented pain in the aforementioned region had signs of myocardial hypoirrigation meaning ischaemia, lesions or sequelae. This

\footnotetext{
*Phone: 0722353789
} 
means that we only included the patients with normal EKG for their age.

Therefore, our patient sample consists of the patients who described a recurrent pain in the left thoracicsubclavicular region which consistently bothered them for 15-30 min and whose resting state EKG was normal.

Based on these results, from 2014 to 2016 we acquired a number of 91 patients ( 35 women and 56 men) who we could diagnose with diastolic cardiac dysfunction with conserved ejection fraction. The medical literature mentions that depending on gender, age and medical history the laboratory tests analysis has different interpretations (fig. 1).

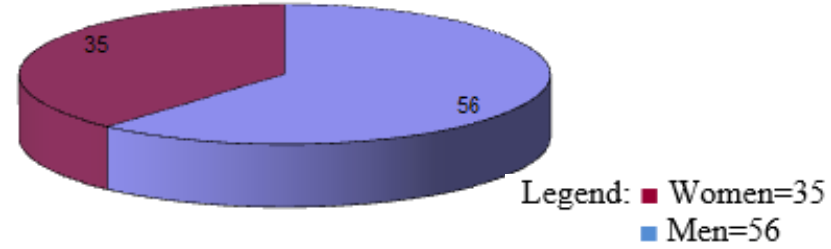

Fig. 1. The composition of the study group in relation to the sex of the patients

We did not include patients aged more than 60 years old, which is in accordance with the majority of studies described by the literature. The average age of our sample was 54.2 years.

We did the following venous blood laboratory tests for the patients part of our study:

- haematology: ESR, haemoleucogram;

- biochemical dosage: cholesterolemia, cholesterol-HDL and $\mathrm{LDL}$-cholesterol, triglyceride, high $\mathrm{C}$ reactive protein (hs-CRP = high sensibility C Reactive Protein), plasmatic fibrinogen oi myeloperoxidase.

Concomitantly, the patients undertook laboratory tests to determine whether there was any signs of hepatocytolysis (TGO, TGP, alkaline phosphatase) or a functional hepatic deficit(serum proteins electrophoresis, plasma fibrinogen).

Undertaking these tests is justified since the liver is involved in the lipids metabolism, and in the patients with chronic hepatic diseases the circulating lipids would be lower. All the patients included in our study had normal hepatic function.

For the myeloperoxidase dosage we used immunofluorescence (FEIA), which used purified MPO from human neutrophils as an antigen. This method quantifies anti-MPO antibodies, who are involved in vascular inflammation pathogeny as responsible coparticipants in endothelial dysfunction aetiology in arteriosclerosis, as reported by the literature.

\section{Results and discussions}

We decided to only include the patients whose ventricular diastolic dysfunction featured a conserved ejection fraction in order to focus on the oxidant production source which is the myocardium under mal-irrigation conditions. This is because it has been postulated that cardiac insufficiency and the reduction in the systolic debit contribute to the systemic production of oxidant agents, even when the organism functions under hypoxic conditions and the respiratory muscles have to maintain a high inspiration rate in parallel with the atrophic process happening in the skeletal muscles [8].

The analysis of the circulant total cholesterol highlighted that 80 patients $(87.9 \%$ cases) showed high cholesterol values and only 11 patients (12\%) had results which would impose a correction of their unhealthy eating habits.
The high number of patients and the raised concentrations of the total cholesterol imposed us to look at total cholesterol/ cholesterol-HDL, and stratify the values obtained from this ratio into risk $[10,11]$.

The values of this ratio indicated the presence of medium + moderate + high risk at 78 patients $(85.5 \%)$, which is correlated to high cholesterol levels in 80 cases (87.9\%). The present data highlights that total cholesterol can indicate the risk of dynamically developing arteriosclerosis, and even by neglecting to take HDL-cholesterol values into account we can indirectly say that a reduction of HDL cholesterol indicates the progression of the risk for dysfunctional irrigation, given by the development of arteriosclerosis.

The dispersion of the values of LDL-cholesterol was looked at in 74 patients (81.1\%) who had higher values than normal. This means that out of 11 patients with diastolic ventricular dysfunction with conserved ejection fraction only 2 had higher LDL-cholesterol.

Nearly a third of our cases $(30.7 \%)$ had normal triglyceride values, and the rest of the patients (69.2\%) had values higher than normal, out of which a third had very high values. One patienthad familial hypertriglyceridemia, and he constantly presented with triglycerides valuing 4178 $\mathrm{mg} / \mathrm{dL}$, which would be therapeutically solved by lipid plasmapheresis.

The presence of relatively similar hyper LDL cholesterol and hypertriglyceridemia values made us consider whether one of these circulating fractions could be specific to the disorder studied, the diastolic ventricular dysfunction with conserved ejection fraction.

Statistically, the incidence of total cholesterol/HDLcholesterol indicates a medium and high risk was correlated with similar risks given by hs-CPR values in 74 patients (81.4\%).

The stratification of the patients in relation to the established risk groups based on the hs-PCR highlighted a significant risk for 74 patients (81.4\%). Out of these, 28 $(30.8 \%)$ had high risk. The statistical significance of these results entitles us to support the practical usefulness of establishing a positive diagnosis for ischemic cardiopathy, especially for the patients who had no signs of ischemia at the EKG test. Moreover, our results allow us to consider serum hs-PCR dosage is a test which appears positive precociously where there are coronary arteriosclerotic regions, since from an electrocardiographic point of view the modification of the repolarisation phase cannot be highlighted.

Based on the medical literature looking at vascular and heart diseases, which feature $C$ reactive protein as an inflammatory marker, the pathogenic source of hs-PCR raised levels in diastolic ventricular dysfunction with conserved ejection fraction can only be attributed to the inflammatory disorder of the myocardium which was induced by ischemia, via the oxidative stress.

The MPO quantification with immunofluorescence (FEIA) highlighted a superior level of $7 \mathrm{U} / \mathrm{mL}$ in 67 cases. This is 2.7 more than the cases with negative results. For the circulating MPO the percentage of positive results is $73.6 \%$ and it indicates that for the patients suffering with chronic diastolic dysfunction caused by ischaemic cardiopathy, which conserves the systolic debit volume, the FAIA test is more sensitive compared with when applied in cases where there are electrocardiographic ischaemic lesions. Even though we believe our sample size is small, we believe that due to the significance of our results, MPO could be used as a diagnosis and risk biomarker for the diastolic ventricular dysfunction with conserved ejection fraction. 


\begin{tabular}{|c|c|c|}
\hline Determined biomarker & $\begin{array}{c}\text { Information on the dynamics of the } \\
\text { disease }\end{array}$ & $\begin{array}{l}\text { Utility of the therapeutic practice/guide } \\
\text { to follow }\end{array}$ \\
\hline$F_{2}$-isoprostans & Long term risk & Requires lifestyle changes \\
\hline microalbumine & Medium term risk: coronary & Early and aggressive treatment \\
\hline hs-PCR & ises developm & \\
\hline MPO & \multirow{2}{*}{\multicolumn{2}{|c|}{ Short term risk: initiation of an acute coronary event }} \\
\hline Lp-PLA & & \\
\hline
\end{tabular}

Table 1

CLINICAL VALUE OF THE CVD MULTIBIOMARKER INFLAMMATORY PROFILE [12]
In supportfor our statements, the multi-biomarker CVD is recommended by the Cleveland Heart Lab to be quantified in the serum together with F2-isoprostatins, microalbuminuria and phospholipase A2 associated with lipoproteins (Lp-PLA $)$ [12-16].

If for the patients with diastolic ventricular dysfunction we analyse the four aforementioned parameters (EKG, electrocardiogram, serum dosage of hs-PCR and MPO) we believe a complex biomarker is formed, and its value lies in the fact that it increases the chances for having an early reliable diagnosis [17-21]. The medical literature highlights the importance of complex biomarkers which on one hand allow the stratification of risks and on the other hand point towards therapeutic opportunities as early as possible (table 1).

Through the present study we illustrate that complex biomarkers could be useful for the diagnosis and evolution of ventricular diastolic dysfunction with conserved ejection fraction.

\section{Conclusions}

We believe that consulting a patient with pain in the left hemithoracic region, where this does not overlap with the classic angor pectoris and where there are no electrocardiographic signs of ischemia, it is a necessity to undertake the dosage of serum hs-PCR, which would exclude the possibility of the diagnosis being ischaemic caridopathy, This test would help establish an early diagnosis and evaluate the coronary risk. This recommendation is supported by a strong correlation between serum hs-PCR and the electrocardiographic test results.

The serum concentration of myeloperoxidase is an indicator useful for stratifying the risks in patients with pain in the superior left hemithoracic region, especially subclavicullary.

Although our study has limitations, such as not including CK-MB or troponins serum dosage, our data illustrate that high myeloperoxidase and hs-PCR serum levels urge us to determine calcium levels and CVD Inflammatory Profile biomarkers too.

Through this study we highlight that the presence of ischaemic cardiopathy can be clinically presented as a stabbing pain in the superior left hemithoracic region and MPO can be used as a biomarker.

\section{References}

1. BALAET C., COCULESCU B.I, BALAET M., MANOLE G., DINCA V.G.

- Haemolytic anaemia and hepatocitolysis associated with hypermagnesaemia by repeated exposures to copper-calcium fungicides. J. Enzyme Inhib. Med. Chem. 2018, 33(1):184-189.

2. BALAET C., COCULESCU B.I, MANOLE G., BALAET M., DINCA V.G., Gamma-glutamyltransferase, possible novel biomarker in colon diverticulosis: a case-control study. J. Enzyme Inhib. Med. Chem. 2018, 33(1): 428-432.

3. DUNCHEN MR.- Mitochondria and calcium: from cell signalling to cell death. J. Physiol 2000; 529:57-68.

4. MANOLE G. - Clinical physiology. Vol. 2. Bucharest (Romania): National Company Printers, Coresi S.A. Publishing; 2007.
5. RUDE MK, DUHANEY TA, KUSTER GM, JUDGE S, HEO J, COLUCCI WS, SIWIK DA, SAM F.- Aldosterone stimulates matrix metalloproteinases and reactive oxygen species in adult rat ventricular cardiomyocytes. Hypertension 2005; 46(3):555-61.

6. BRAUNWALD E. - Biomarkers in heart failure. N. Engl. J. Med 2008; 358: 2148-59.

7. MADJ ID M, WILLERSON JT. - Inflammatory markers in coronary heart disease. Br Med Bull. 2011; 100:23-38.

8. MANOLE G. - General clinical pathophysiology (Pathophysiology Organs). Vol. II. Bucharest: National Company Printers, Coresi S.A. Publishing. 2003.

9. MOHAZZAB KM, KAMINSKI PM, WOLIN MS. - NADH oxidoreductase is a major source of superoxide anion in bovine coronary artery endothelium. Am J Physiol 1994; 266(6 Pt 2):H 2568-H 2572.

10. MILLER NE. - Association of high density lipoprotein subclasses and apolipoproteins with ischemic heart disease and coronary atherosclerosis. Am Heart] 1987; 113(2 Pt 2):587-97.

11. GORDON DJ, RIFKIND BM. - High density lipoprotein-the clinical implications of recent studies, N Engl J Med 1989; 321(19):1311-6.

12. HUGHES S, WOOD S. - A multibiomarker test for predicting CVD: Has its time arrived?; 2012. Available from: https://www.medscape.com/ viewarticle/791243.

13. COCULESCU B.I., MANOLE GH., DINCA V.G., COCULESCU C.E., BERTEANU C., STOCHECI M.C. - Osteopontin-a biomarker of disease, but also of stage stratification of the functional myocardial contractile deficit by chronic ischaemic heart disease - Journal of Enzyme Inhibition and Medicinal Chemistry - ISSN: 1475-6366; Volume 34, 2019 - Issue 1; pg. 783-788

14. COCULESCU B.I, DINCA V.G., BALAET C., MANOLE G., BALAET M., STOCHECI C.M. - Myeloperoxidase, a possible biomarker for the early diagnosis of cardiac diastolic dysfunction with conserved ejection fraction. J Enzyme Inhib Med Chem. 2018, 33(1):1292-1298. 15. COCULESCU, B.I, DINCA, V.G., MANOLE, G., PURCAREA, V.L., STOCHECI, C.M., Serum concentration of hSCRP - possible marker for therapy evaluation in left ventricular dysfunction with preserved ejection fraction - Rev.Chim. (Bucharest), 69, no.10, 2018, p.28852890.

16. DINCA, V.G., MANOLE, GH., COCHIOR, D., DINCA ,A.L., Growth differential factor 15 (GDF-15), possible biomarker in heart failureRev.Chim.(Bucharest), 68, no. 3 , 2017, p.631-634;

17. DINCA, V.G., MANOLE, GH., COCHIOR, D., DINCA, A.L., Paraoxonase (PON1) possible biomarker for risk of heart failureRev.Chim.(Bucharest), 67, no. 5, 2016, p.854-857;

18. CAPITANESCU C., MACOVEI OPRESCU A. M., IONITA D., DINCA G.V., TURCULET C., MANOLE GH., MACOVEI R. A. - Molecular process in streptokinase thrombolytic therapy - J ournal of Enzyme Inhibition and Medicinal Chemistry - ISSN: 1475-6366; Volume 31, 2016 - Issue 6; pg. 1411-1414;

19. DINCA G., SURDU T.V., IONESCU E.V., CATALIN G., MANOLE G., Rolul membranelor celulare in apoptoza cardiomiocitelor in cardiopatia ischemica cronica - Revista Medicina Moderna ISSN 12230472; 2013 Vol.XX-Nr.3,pg.158-160,

20. DINCA V.G., MANOLE G.,Organ failure as an expression of organ remodeling. Involvement of oxidative stress - J ournal of Medicine and Life ISSN 1844-122x; 2013; Volume 6, Issue 3, July-September; pg.240-243.

21. COCULESCU, B.I., MANOLE, G., HARSOVESCU, T., TUDORACHE, I.S., TONE, M.B., DINCA, A.L.,Considerattions on the ethiopathogenesis of algae from the primary form of BMD, Rev.Chim. (Bucharest), (in press) 